\title{
Unmet needs among Danish women with breast cancer in the transition from diagnosis into the early treatment phase
}

\author{
Mikael Birkelund Jensen-Johansen ${ }^{1}$, Jette Henriksen*2, Ingrid Villadsen Kristensen ${ }^{3,4,5}$, Anette Meldgaard ${ }^{2}$, Trish \\ Livingston $^{6,7}$, Bodil Rasmussen $6,7,8,9$ \\ ${ }^{1}$ Research Centre for Health and Welfare Technology, VIA University College, Holstebro, Denmark \\ ${ }^{2}$ Research Centre for Health and Welfare Technology, Program for Ageing, VIA University College, Holstebro, Denmark \\ ${ }^{3}$ VIA Nursing Programme in Holstebro, Denmark \\ ${ }^{4}$ Research Centre for Health and Welfare Technology, Program for Rehabilitation, VIA University College, Denmark \\ ${ }^{5}$ Regional Hospital West Jutland, Denmark \\ ${ }^{6}$ Faculty of Health, Deakin University, Australia \\ ${ }^{7}$ Faculty of Health and Medical Sciences, University of Copenhagen, Denmark \\ ${ }^{8}$ The Centre for Quality and Patient Safety Research in the Institute of Health Transformation, Western Health Partnership, \\ Western Health, Australia \\ ${ }^{9}$ Faculty of Health Sciences, University of Southern Denmark, Denmark
}

Received: August 25, 2021

DOI: $10.5430 /$ jnep.v12n3p1
Accepted: October 8, 2021

Online Published: October 22, 2021

\begin{abstract}
This study investigates the supportive needs of women diagnosed with breast cancer in the early treatment phase. The aim of this study was to identify unmet supportive care needs in the early treatment phase of women treated for breast cancer. This study employed a quantitative longitudinal design with baseline questionnaire (Time 1) and a six-month follow-up questionnaire (Time 2) that explored a variety of characteristics using both standardized scales and more explorative questions about employment situation, needs, rehabilitation, psychological, physical and social experiences. Eighty-five percent of the invited potential women agreed to participate, and 100 participants completed the baseline questionnaire. The analysis identified results concerning employment situation, depressive symptoms, unmet needs, distress, sexual life, social constraints and cancer-related quality of life. The study concludes that health professionals must embrace the challenges faced by the women and provide strategies to support women achieving meaningful lives.
\end{abstract}

Key Words: Breast cancer, Life transition, Psychological well-being, Unmet needs, Denmark

\section{INTRODUCTION}

Breast cancer is the most common malignant disease and leading cause of cancer mortality in women. ${ }^{[1]}$ In addition, there are one million new cases in the world each year, and breast cancer therefore represents a major public health issue. ${ }^{2]}$ Improved treatment and screening programs have increased the number of breast cancer survivors and transformed breast cancer diagnosis from being regarded as an

\footnotetext{
*Correspondence: Jette Henriksen; Email: jhen@via.dk; Address: Research Centre for Health and Welfare Technology, Program for Ageing, VIA University College, Gl. Struervej 1, 7500 Holstebro, Denmark.
} 
acute illness to a more complex and chronic condition with people living longer and experiencing more illness related physical, socially and psychological side effects. ${ }^{[3,4]}$ The transition from a healthy woman to being diagnosed with breast cancer with a potentially fatal illness can be very stressful. To become a breast cancer survivor with ongoing follow-up consultations, can add stress and may be potentially a disempowering experience and require the women to go through a transition from perceiving herself as a healthy woman to living with a chronic condition. ${ }^{[5]}$ It has physical, psychological and social implications for the women, who receive a cancer diagnosis and It also add restrictions their daily life such as disruption in social activities and decrease their capacity to plan. ${ }^{[6,7]}$ The women might also be further restricted by the physical symptoms, such as fatigue, nausea, vomiting, weight gain, hair loss, that the treatment often extracts. ${ }^{[6]}$ Emotional distress and lower quality of life among people diagnosed with breast cancer is well established in the literature ${ }^{[8,9]}$ and along with higher levels of psychological distress, depression and anxiety. ${ }^{[10,11]}$ Higher levels of distress, depressive symptoms and decreased quality of life is evident several years after completing treatment and has an impact on woman's return to normal life in several ways, ${ }^{[8,9]}$ for example, the need for general rehabilitation, income and returning to the work force. ${ }^{[12]}$ Previous research has investigated the transitional experience and health care needs in people undergoing chemotherapy. ${ }^{[5,13]}$ Nevertheless, the current study seeks to identify unmet supportive care needs in the early treatment phase of women treated for breast cancer. Little is known about the unmet physical, physiological and social needs in the very early treatment phase a few weeks after diagnosis. ${ }^{[14,15]}$ In this early phase the prevalence of different unmet needs could depend on several factors like severity of the cancer, treatment protocols, sociodemographic and comorbidity.

The aim of this study was to identify unmet supportive care needs in the early treatment phase of women treated for breast cancer. The secondary objectives were to investigate differences in supportive needs between groups treated with chemotherapy and radiation-therapy, and to compare levels of unmet needs in the early treatment phase with levels in the post-treatment phase.

\section{MethodS}

This paper presents the second part of a study investigating the transition experience of women with breast cancer. The first part of this study was a qualitative study revealing detailed insights into the psychosocial health care needs in a group of women newly diagnosed with breast cancer during their primary treatment. These results are presented else- where. ${ }^{[5]}$ In this paper, only the second part, a quantitative longitudinal part of the study is presented. This part investigates the supportive needs of people diagnosed with breast cancer in the early treatment phase of their condition.

\subsection{Design}

A quantitative longitudinal design with baseline questionnaire (Time 1) and a six-month follow-up questionnaire (Time 2) was used to explore a variety of characteristics using both standardized scales and more explorative questions about employment situation, needs, rehabilitation, psychological, physical and social experiences. All items and scales in the final questionnaire were selected carefully after reviewing the literature in the area of breast cancer survivorship and the results from the first part of our study on transitional experiences. ${ }^{[5,16]}$

\subsection{Participants}

Over a six-month period, 123 Danish women diagnosed with breast cancer, treated with mastectomy or lumpectomy, were assessed for eligibility during their primary treatment period. The inclusion criteria were: age between 25 and 70 years old, able to read and understand the information involved in the research, no previous cancer diagnosis and newly diagnosed with breast cancer. All women lived in a regional area and attended the regional oncology clinic. All women were undergoing either chemo- or radiation treatment.

\subsection{Data collection}

The clinic nurses screened the patient list at the Oncological outpatient Clinic in a Regional Hospital in West Jutland in Denmark, according to the inclusion criteria and provided both written and oral information to the patients about the project. Women who indicated their interest in participating were provided with consent forms and given the baseline questionnaires by the clinic nurses. The questionnaires were completed at the middle of the primary treatment period (at the first of three treatments for chemo patients and in the beginning of the third of five weeks with radiation for the radiation patients).

All women were encouraged to bring the questionnaire package home for consideration before they decided whether to participate or not. The ward nurses received consent forms and the questionnaires at the next treatment and registered all participants and non-participants. Non-responders were reminded and encouraged to bring the questionnaire and consent form at the next treatment. Only ten women required a reminder. The data from the baseline questionnaires were collected from February 2014 through September 2014.

The follow-up questionnaire was mailed by postal service to 
the women six months after completing the baseline questionnaire. Non-responders were reminded by postal mail after 4 weeks and again after 8 weeks. The data from the Followup questionnaires were collected from October 2014 through marts 2015 .

Questionnaires were produced and scanned electronically (Teleform Software) by a professional staff at The Unit for Psychooncology and Health Psychology, Aarhus University.

\subsection{Ethical considerations}

All data collected were stored according the guidelines of the Danish Data Protection Agency and according to the guidelines from the National Ethics Committee, Danish laws ${ }^{[17]}$ and the Helsinki Declaration. ${ }^{[18]}$ All women received oral and written information about the study before giving written informed consent. Participants were advised of the voluntary nature of the study and their right to withdraw at any time. The women were invited to participate by a nurse in the oncology clinic. The nurse was not directly involved in the care of the potential participants. Hereafter, the women received written and oral information about the study. Furthermore, the women were given time to consider participation in the study after being informed about anonymity, confidentiality and privacy.

\subsection{Instruments}

Demographic information including items concerning socioeconomic status, working hours, marital status, education level, income status and treatment status.

The Supportive Care Needs Survey (SCNS-SF34 with simplified response format) is a brief 34 item instrument for assessing the perceived needs of people diagnosed with cancer. It consists of 34 items from five different domains of needs including Psychological, Health system \& Information, Physical \& Daily living, Patient care \& Support and Sexuality. Among the instruments available to evaluate supportive care needs as applied to cancer, the Supportive Care Needs Survey (SCNS), developed by Girgis and her Australianbased team ${ }^{[19]}$ appears to reach the optimum level of validity and reliability. ${ }^{[20]}$ The short version of 34 items has been validated psychometrically in its original language, and also in Japanese and Chinese. ${ }^{[19,21-26]}$ The original SCNS-SF34 uses a five point, two-level response scale with two broad categories of need: 'no need' and 'need'. The 'need' category consists of three subcategories: 'low need', 'moderate need' and 'high need'. The 'no need' category consists of two subcategories: 'no need' and 'satisfied'. Patients find this response scale as confusing and difficult to complete. ${ }^{[21]}$ Especially the 'no need' subcategories are difficult and patients finds it hard to differentiate between an absence of need and needs that have already been satisfied. In accordance with Shofield et al. 2012, we used the simplified four-point version without the confusing 'no need': 'satisfied' subcategory in our Danish Translation of the SCNS SF34. The simplified version maintained the same factor structure and is reliable, valid and more acceptable to cancer patients than the original with five-point response scale. ${ }^{[21]}$

Depressive symptoms were measured with the short 13-item version of the Beck Depression Inventory (BDI-SF) ${ }^{[27-29]}$ which is one of the most widely used measures of depression. The BDI has been translated into Danish using the translation-back translation method and has been used in studies with Danish patients and volunteers. ${ }^{[30]}$ The items stem from the BDI-I and only the total score is calculated. It is of the grouped into 'none or minimal' (score 0-4), 'mild' (5-7), 'moderate' (8-15), and 'severe depression' (16+), but with a cut-off point at 9/10 it has been found to include some false positive cases, and with a 13/14 cut-off point to leave some depressive undetected. ${ }^{[31]}$

Cancer-related psychological distress was measured with The Impact of Events Scale-Cancer (IES-C). ${ }^{[32]}$ The IES-C is a standardized measure of current subjective distress related to a traumatic experience and measures intrusive and avoidance symptoms experienced in the previous 7 days. The items of the IES-C were anchored to the specific stressor of having been diagnosed with breast cancer. The combined score (avoidance + intrusion) provides a total cancer-related distress score. The IES-C total is considered as subclinical 'scores' (0-8), 'mild' (9-25), 'moderate' (26-43) and 'severe' $(44+)$.

Health related quality of life was measured with the European Organization for research and Treatment of Cancer Quality of Life Core Questionnaire (EORTC QLQ-C30), developed to assess the quality of life of cancer patients. It has been translated and validated into 49 languages, including Danish, ${ }^{[33]}$ and is used in more than 3000 studies worldwide. The EORTC- QLQ-C30 includes subscales of Global health status (QoL), five functional scales: physical functioning, role functioning, cognitive functioning, and social functioning, and a number of scales and items covering symptoms, including fatigue, nausea, appetite loss, and insomnia. ${ }^{[34]}$ The calculated total score of global health status was used as outcome measure in the present study.

The Social Constraints Scale (SCS-C) measures how often the individual perceives the social environment to influence her attempts to talk about a traumatic experience. ${ }^{[35,36]}$ In this version, the respondent was asked 5 questions about the constraining effect of the social environment on attempts to talk about breast cancer. The five items were repeated 
twice, once with respect to the 'most important person' (e.g. spouse/partner) and once with respect to 'other people' and a total score was calculated.

Sexual life is a single item question rated on a 3-point likert scale: "How would you describe your sexual life before the operation?" (very satisfactory/somewhat satisfactory/not satisfactory). At Time 1 this question is asked retrospectively, but at Time 2 the question is asked in present tense. The self-rated experience of sexual life satisfaction can be considered as a trustworthy measure of general quality of life, and can often reveal if the informants are overstating their scores in other quality of life measures with no items of sexual satisfaction. Questions about sexuality can however be controversial and are often linked to social taboo which can result in many missing entries in this item. ${ }^{[37]}$

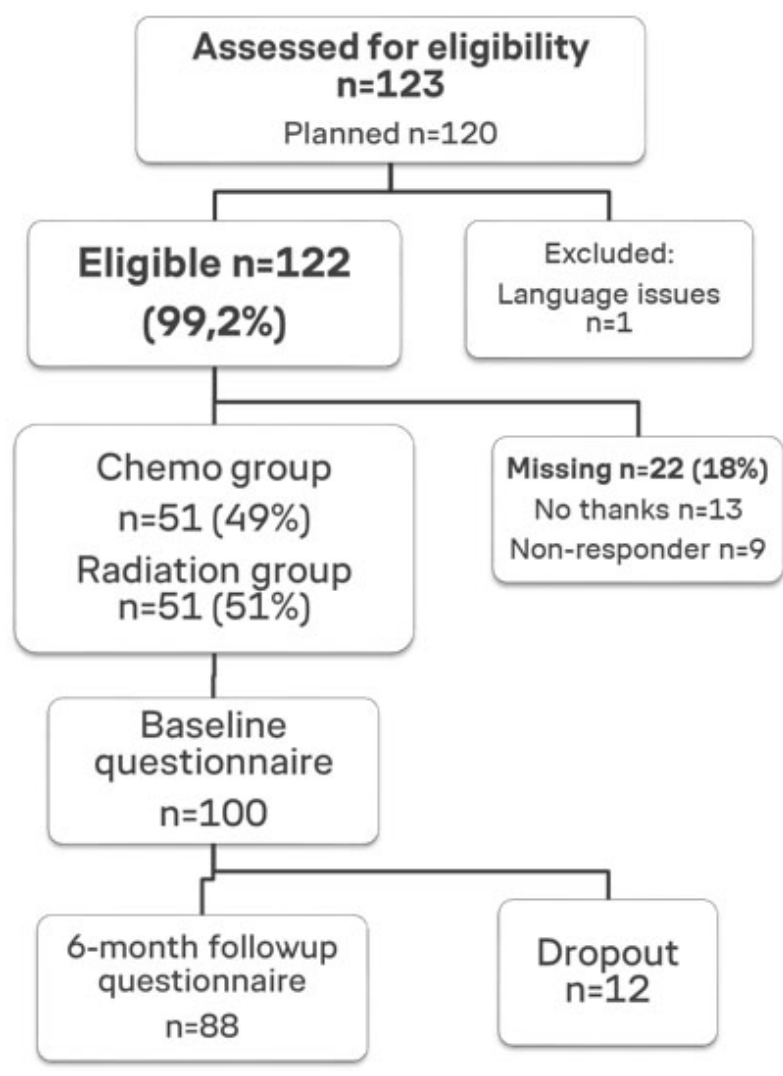

Figure 1. Flow chart

\subsection{Analyses}

A t-test was performed on primary outcomes. Non-normal scales were log-transformed prior to analysis. Subscale totals with more than $50 \%$ missing values were coded as missing, and no total score was calculated. If missing values were $50 \%$ or less on a subscale, they were substituted with the mean of the remaining filled items on the subscale for each case. This procedure is preferable to procedures such as list- wise deletion or scale mean-substitution of scale-score when one or more values are missing. ${ }^{[38]}$ Dropouts were assumed not missing at random and were administered with list-wise deletion in all analyses. All analyses were made with IBM SPSS Statistics version 24.

\section{Results}

Eighty-five percent of the invited potential women agreed to participate, and 100 participants completed the baseline questionnaire. Forty-nine women were under treatment with chemotherapy, forty-five with radiation-therapy and four women were treated with both chemo- and radiation-therapy. Hormone treatment is combined with radiation-therapy and 26 out of 28 patients treated with hormones are also treated with radiation and are thus not treated as a separate group in this study. Twelve women dropped out of the study for unknown reasons. The mean age differed between groups, with 66 years in radiation group and 53 years in chemotherapy group. All demographics results are presented in Table 1: Descriptive data.

Only $20 \%$ of the participating women were single and more than a third with high education degree (Master level).

\subsection{Employment situation}

More women in the chemotherapy group, compared to the radiation group, had higher level of education and more women in the chemotherapy group were active in the labor market before diagnosis as well as after diagnosis. More women in the radiation group were retired and 22 percent of the women were working full-or part-time after their diagnosis (Time 1), however twice as many (46\%) were employed 6 months later (Time 2), and only $13 \%$ were on sick leave compared to $33 \%$ at Time 1. The mean working hours dropped by half from before diagnosis (retrospective baseline) to after diagnosis (Time 1). At Time 2 the mean working hours were back at the same level as before diagnosis.

\subsection{Depressive Symptoms (BDI-SF)}

A paired-samples t-test was conducted to evaluate the impact of time on participants' scores on the Beck Depression Inventory Short Form (BDI-SF). There was a statistically significant decrease in BDI-SF from Time $1(\mathrm{M}=4,3, \mathrm{SD}=$ $3,7)$ to Time $2(\mathrm{M}=3,2, \mathrm{SD}=3,4), \mathrm{t}(84)=2,4), p>.05$ (two-tailed). The mean decrease in BDI-SF was 0,64 with a $95 \%$ confidence interval ranging from 0,10 to 2,35 . The eta squared statistic (0.01) indicated a small effect size. ${ }^{[39]}$ Only few women scored mild symptoms of depression and the overall mean showed none or minimal symptoms of depression at both Time 1 and Time 2 . 
Table 1. Descriptive data, demographic characteristics of participants and selected results

\begin{tabular}{|c|c|c|c|c|}
\hline & Radiation T1 & Chemo $^{*}$ T1 & Total T1 & Total T2 \\
\hline & $\mathrm{N}(\%)$ & N (\%) & $\mathbf{N}(\%)$ & N (\%) \\
\hline & Mean (SD) & Mean (SD) & Mean (SD) & Mean (SD) \\
\hline Participants N (\%) & 51 & 49 & 100 & 88 \\
\hline Age at study entry, Mean (SD) & $66.3(8.5)^{*}$ & $53.7(8.9)^{*}$ & $59.6(10.7)$ & \\
\hline Age, non-participants $(\mathrm{n}=23)$ & & & $62.4(8.4)$ & \\
\hline \multicolumn{5}{|l|}{ Education, $\mathrm{N}(\%)$} \\
\hline Lower secondary general ( $7-10 \mathrm{yrs}$.) & 17 & 12 & 29 & \\
\hline Vocational school (11-13 yrs.) & 9 & 10 & 18 & \\
\hline Upper secondary school (11-13 yrs.) & 5 & 3 & 8 & \\
\hline Tertiary (14 to 17 yrs, < Master Degree) & 11 & 21 & 32 & \\
\hline Tertiary ( $\geq 18$ years, $\geq$ Master Degree) & 2 & 5 & 7 & \\
\hline Other & 1 & 2 & 3 & \\
\hline Missing & 2 & 0 & 2 & \\
\hline \multicolumn{5}{|l|}{ Marital status, $\mathrm{N}(\%)$} \\
\hline Married or cohabiting & 31 & 42 & 73 & $67(77 \%)$ \\
\hline Single & 16 & 11 & 27 & $20(23 \%)$ \\
\hline \multicolumn{5}{|l|}{ Employment situation before diagnosis, $\mathrm{N}(\%)$} \\
\hline Self-employed & 0 & 3 & 3 & \\
\hline Employee (full time) & 8 & 25 & 33 & \\
\hline Employee (part time) & 6 & 10 & 16 & \\
\hline Unemployed & 0 & 1 & 1 & \\
\hline Old age or early retirement pension & 33 & 11 & 44 & \\
\hline Sick leave (full or part time) & 0 & 1 & 3 & \\
\hline Missing & 0 & 0 & 0 & \\
\hline \multicolumn{5}{|l|}{ Employment situation (present), N (\%) } \\
\hline Self-employed & 0 & 2 & $2(2 \%)$ & $2(3 \%)$ \\
\hline Employee (full time) & 3 & 8 & $11(11 \%)$ & $23(27 \%)$ \\
\hline Employee (part time) & 5 & 4 & $9(9 \%)$ & $14(16 \%)$ \\
\hline Unemployed & 0 & 0 & $0(0 \%)$ & $1(2 \%)$ \\
\hline Old age or early retirement pension & 33 & 11 & $44(44 \%)$ & $36(41 \%)$ \\
\hline Sick leave (full or part time) & 5 & 28 & $33(33)$ & $11(13 \%)$ \\
\hline Missing & & & $1(1 \%)$ & $1(2 \%)$ \\
\hline Weekly working hours before diagnosis, $\mathrm{M}(\mathrm{SD})$ & $24.7(15.5)$ & $31.8(10.9)$ & $29.7(12.7)$ & \\
\hline Weekly working hours (present), M(SD) & $16.3(15.0)$ & $14.1(15.6)$ & $14.8(15.3)$ & $28.5(15.2)$ \\
\hline \multicolumn{5}{|l|}{ Household income (Dkr./US\$) } \\
\hline$<300.000 /<48.000$ & 25 & 8 & 33 & \\
\hline $3-500.000 / 48-79.000$ & 10 & 19 & 29 & \\
\hline $5-700.000 / 79-111.000$ & 6 & 9 & 15 & \\
\hline$>700.000 />111.000$ & 3 & 13 & 16 & \\
\hline Missing & 3 & 4 & 7 & \\
\hline \multicolumn{5}{|l|}{ Type of Surgery, N (\%) } \\
\hline Mastectomy & 2 & 10 & 12 & \\
\hline Tumorectomy & 43 & 43 & 86 & \\
\hline Missing & 2 & 0 & 2 & \\
\hline \multicolumn{5}{|l|}{ Treatment Radiotherapy, N (\%) } \\
\hline Radiotherapy & 45 & 4 & 49 & \\
\hline Chemotherapy & & 53 & 53 & \\
\hline Hormone treatment & 26 & 2 & 28 & \\
\hline \multicolumn{5}{|l|}{$\mathrm{SCNS}(\mathrm{M} / \mathrm{SD})$} \\
\hline Psychological needs & $16.5(6.6)$ & $17.3(6.1)$ & $15.9(5.8)$ & $15.8(6.3)$ \\
\hline Health system and information needs & $24.1(11.7)$ & $21.9(9.9)$ & $21.9(10.5)$ & $18.4(9.0)^{* *}$ \\
\hline Physical and daily living needs & $7.6(3.0)^{*}$ & $9.9(3.5)^{*}$ & $8.5(3.3)$ & $7.8(3.3)^{\#}$ \\
\hline Patient care and support needs & $7.2(3.0)$ & $7.9(3.2)$ & $7.3(3.0)$ & $6.8(2.8)$ \\
\hline Sexuality needs & $3.5(1.4)^{*}$ & $4.8(2.4)^{*}$ & $4.3(2.1)$ & $4.3(2.1)$ \\
\hline Depression (BDI) & & & $4.3(3.7)$ & $3.2(3.4)^{* *}$ \\
\hline Missing & & & $3(3 \%)$ & $14(14 \%)$ \\
\hline Impact of Event Scale (IES) & & & $16.5(13.6)$ & $13.5(13.4)$ \\
\hline Intrusion subscale & & & $7.2(7.5)$ & $6.3(6.6)$ \\
\hline Avoidance subscale & & & $9.1(7.5)$ & $7.1(7.7)$ \\
\hline Hyperarousal subscale & & & $4.8(5.5)$ & $4.1(5.2)$ \\
\hline Social Constraints Scale (SCS) & & & $15.4(6.1)$ & $16.4(6.7)^{\#}$ \\
\hline Other People subscale & & & $7.8(3.1)$ & $8.3(3.2)^{\#}$ \\
\hline Most important person subscale & & & $7.6(3.6)$ & $8.0(3.9)$ \\
\hline Quality of Life (EORTC-QLQ-C30) & & & $69.6(20.6)$ & $73.5(19.2)^{\#}$ \\
\hline
\end{tabular}

*Participants treated with both cancer and radiation $(\mathrm{n}=4)$ were included in this category. *Statistical significant $(p<.05)$ difference between groups (radiotherapy/chemotherapy). Independent samples $t$-test (2-tailed). **Statistical significant $(p<.05)$ difference from T1 to T2. Paired-samples $t$-test (2-tailed).\# Statistical trend $(p<.1)$ difference from T1 to T2. Paired-samples $t$-test (2-tailed). 


\subsection{Unmet needs}

The subscales of the SCNS revealed good reliability (Cronbach's alpha: .79 - .96) and the summated scores were skewed and consequently log-transformed. An independent samples $t$-test were conducted to compare the need scores for radiotherapy-group (R-group) and the chemotherapy group (C-group).

There was a significant difference between the Chemo-group and Radiation-group on physical and daily living needs [ $\mathrm{t}(93)$ $=-3,24, p=.002]$ and sexuality needs $[\mathrm{t}(90)=-3.36, p=$ $.001]$, but the magnitude of the differences in the means were small (eta squared $=0.10 \& 0,11$ ). ${ }^{[39]}$ After correction for age, only physical and daily living needs remained as a statistically significant difference between the two groups over time, indicating that the Chemo-group remained with a higher degree of need than the Radiation-group regarding physical and daily living needs.

When collapsing the Radiation-group and the Chemo-group, to run a paired-samples t-test to evaluate the impact of time on participants' scores on the SCNS, we found a statistically significant decrease in health system and information needs from Time $1(\mathrm{M}=21.9, \mathrm{SD}=10.5)$ to Time $2(\mathrm{M}=18.4$, $\mathrm{SD}=9.0), \mathrm{t}(84)=3.36), p<.05$ (two-tailed). The mean decrease was 3.5 with a $95 \%$ confidence interval ranging from 1.41 to 5.51 . The eta squared statistic (0.03) indicated a small effect size. ${ }^{[39]}$ None of the other subscales revealed any statistically significant change over time, however the physical and daily living needs revealed a statistically trend indicating a very small decrease over time (see Table 1).

Table 2. SCNS subscales $(\mathrm{N}=98)$ at Time 1

\begin{tabular}{|c|c|c|c|}
\hline \multirow{2}{*}{ SCNS sub scales } & No needs & Low to moderate need & Moderate need or more \\
\hline & N (\%) & N (\%) & $\mathbf{N}(\%)$ \\
\hline No needs reported on any items & $7(8)$ & & \\
\hline Psychological needs & $17(18)$ & $31(32)$ & $3(3)$ \\
\hline Health system and information needs & $17(18)$ & $19(20)$ & $27(28)$ \\
\hline Physical and daily living needs & $25(26)$ & 32 (33) & $8(9)$ \\
\hline Patient care and support needs & $34(35)$ & $13(14)$ & $6(7)$ \\
\hline Sexuality needs & $64(66)$ & $12(13)$ & $7(8)$ \\
\hline
\end{tabular}

Only $8 \%$ of the women reported no unmet needs at time 1 (see Table 2) compared to $12 \%$ of the women at time 2 (data not shown) which indicates that almost all women in the early treatment phase experienced some needs unmet.

\subsection{Distress (IES)}

A paired-samples t-test was conducted to evaluate the impact of time on participants' scores on the Impact of Events Scale (IES). There was no statistically significant decrease in total IES from Time $1(M=16,5, S D=13,6)$ to Time $2(M=13.5$, $\mathrm{SD}=13.4), \mathrm{t}(83)=0.92), p=.36$ (two-tailed). The mean decrease in IES was 0,99 with a $95 \%$ confidence interval ranging from $-1,17$ to 3,15 . None of the three subscales Intrusion, Avoidance or Hyperarousal revealed any statistically significant decrease (see Table 1). The overall mean reveals mild distress symptoms at both Time 1 and Time 2 and only a few women with moderate distress symptoms.

\subsection{Social Constraints (SCS)}

A paired-samples t-test was conducted to evaluate the impact of time on participants' scores on the Social Constraint Scale (SCS). There was a statistically non-significant trend indication an increase in total SCS from Time $1(\mathrm{M}=15,2, \mathrm{SD}=$
5,8) to Time $2(\mathrm{M}=16,4, \mathrm{SD}=6,7), \mathrm{t}(84)=-1,86), \mathrm{p}=0,07$ (two-tailed). The mean decrease in SCS was $-1,13$ with a $95 \%$ confidence interval ranging from $-2,33$ to 0,08 . The eta squared statistic $(0,01)$ indicated a small effect size. ${ }^{[39]}$ This trend was also found in the subscale 'Other People', but not in the subscale 'Most important person' (see Table 1).

\subsection{Cancer-related Quality of Life (EORTC QLQ-C30)}

A paired-samples t-test was conducted to evaluate the impact of time on participants' scores on the Quality of life scale (EORTC QLQ-C30). There was a statistically nonsignificant trend indicating an increase in total QoL from Time $1(\mathrm{M}=68.4, \mathrm{SD}=21.0)$ to Time $2(\mathrm{M}=73.5, \mathrm{SD}$ $=19.2), \mathrm{t}(84)=-1.798), p=.08$ (two-tailed). The mean increase in QLQ was $-3,92$ with a 95\% confidence interval ranging from $-8,26$ to 0,41 . The eta squared statistic $(0,01)$ indicated a small effect size ${ }^{[39]}$ (see Table 1). The overall mean score is considered within the normal range, compared to the general Danish population. ${ }^{[40,41]}$

\subsection{Sexual Life}

A paired-samples t-test was conducted to evaluate the impact of time on participants' level of sexual life satisfaction. 
There was a statistically significant decrease from Time 1 $(\mathrm{M}=2,38 \mathrm{SD}=0,7)$ to Time $2(\mathrm{M}=1,8 \mathrm{SD}=0,7), \mathrm{t}(44)=$ $5,83), p=.00$ (two-tailed). The mean decrease was 0.62 with a $95 \%$ confidence interval ranging from 0,11 to 0,84 . The eta squared statistic $(0,38)$ indicated a large effect size, ${ }^{[39]}$ indicating a significant decrease in satisfaction with sexual life six month post-surgery.

\section{Discussion}

To our knowledge, this is the first study to investigate unmet needs in the very earliest treatment phase among Danish women with breast cancer using the validated SCNS-34 short version.

The results concerning distress, indicate that participants experienced low grade levels of distress and depression in the early phase after diagnosis. Importantly, both the low grade of distress and symptoms of depression eased rapidly and in addition, there was therefore no significant difference between women in chemo - and radiation treatment when data was adjusted for age. The overall mean reveals mild distress symptoms at both Time 1 and Time 2 and only a few women with moderate distress symptoms. These findings are consistent with other findings with Danish breast cancer patients. ${ }^{[42]}$

In relation to unmet needs, our results indicate that women receiving chemo treatment, had a higher degree of need than the women receiving radiation treatment regarding physical and daily living needs. The patient perspective is an important parameter when assessing the quality of healthcare concerning unmet needs. Information directly from the patients themselves, is increasingly in demand and constitutes a unique source of information to e.g. knowledge of patient needs and unmet needs. ${ }^{[43]}$ Our results indicate that women have unmet needs during the process of treatment. These results can be seen in the context of transition. According to Meleis, transitions can be considered as movement and flow over time. ${ }^{[44]}$ Transitions are characterized by periods during which persons make the shift from one life phase, situation, or status to another as well as periods of vulnerability to risks inherent in health and the change from health to illness. Patients may go through phases of uncertainty, confusion, and anxiety during the transition, before they can enter a new beginning. ${ }^{[44]}$ Besides, patients in transition tend to be more vulnerable ${ }^{[44]}$ hence the process of being treated for breast cancer concerns related to identity as findings from the first part of our study, there was an immense psychological impact reported by the women related to them experiencing great sense of uncertainty, sense of powerlessness, difficulties in sustaining normality and also worried about their future. ${ }^{[5]}$ In this qualitative study the women managed their transition

Published by Sciedu Press by trying to establish normality in their everyday life. These findings were also aligned in the in current study as employment was a significant contributor in the process towards establishing normality in their everyday life. The transition to living with a cancer diagnosis was also marked by finding ways to maintain their identity. Employment plays an important role to assist women maintain their identity which was strongly linked to being employed or even being engaged in voluntary work. ${ }^{[5]}$ Other research indicates that employment situation is a major factor affecting general wellbeing and rehabilitation. ${ }^{[45,46]}$ Being employed and getting back to work can be crucial for a positive trajectory or outcome of the transition, as working can be a sign of normality. ${ }^{[5]}$ Furthermore, participation in the workforce is a very important factor impacting on the women's experience of living a normal and meaningful life. ${ }^{[47]}$ The women's decisions about working were affected during the treatment phase due to uncertainties and worries about ability to work, possible job loss and physical appearance. ${ }^{[47]}$ In our study $13 \%$ of women were on sick leave 6 months after diagnosis. This suggests that women's work situation is important to address during the process of treatment. There is a discrepancy in employment rate in prior to and after the breast cancer treatment with only $46 \%$ of women reported returning back to the work force after 6 months compared to 53\% before diagnosis. Women with breast cancer have been found to have higher levels of unemployment after breast cancer treatment and also slower return to employment than other patient groups. ${ }^{[47,48]}$

Our results also suggest a significant decrease in satisfaction with their sexual life six-month post-surgery. Interestingly, more than half of the women in our study responded with a 'don't know' or 'not relevant' on the questions related to the sex life. An integral part of people identity is our sexuality ${ }^{[49]}$ with research literature indicating that a high number of women experienced problems related to their self-concept and sexual health secondary to breast cancer. ${ }^{[49]}$ However, the women reported inadequate response from health professionals when sexuality were raised in the conversations. ${ }^{[49]}$ Women with breast cancer clearly need support to get back into employment, more information or communication about factors related to sex life after treatment following a cancer diagnosis and support to sustain their identity in the new life phase as living with a breast cancer diagnosis.

Health professionals need to consider an individualised plan of care that consider the women are in transition with different care needs that constantly change in weeks after diagnosis depending on the woman's' social, psychological, and physical circumstances. 


\section{CONCLUSIONS AND IMPLICATIONS FOR PRACTICE}

Our study indicates that women receiving chemo treatment, had a higher degree of need than the women receiving radiation treatment regarding physical and daily living needs. Furthermore, our results indicate that women have unmet needs during the process of treatment. Women with breast cancer clearly need support to get back into employment, more information or communication about factors related to sex life after treatment. Our results suggest that the woman's transitional experience from time of diagnosis to six months' post diagnosis experience is contextual and individual. Their particular experience of unmet needs is strongly influenced by a range of factors, e.g., treatment type(s), relationship status and age with the need for post treatment being employment.

The results suggest a gap between the unmet needs of women with breast cancer in the early transitional phase to living with breast cancer and the healthcare systems' response their needs. To meet this gap, health professionals must embrace the challenges faced by the women and provide strategies to support women achieving meaningful lives. More focus on sexual needs during this transition period is needed as well as supportive strategies to return to work. An approach that supports and focuses on psychological and social unmet needs is a priority in the post treatment care among this group of women living with breast cancer.

\section{FUNDING}

This work was supported by Research Centre for Health and Welfare Technology, Program for Ageing, and the Nursing Programme in Holstebro, VIA University College Denmark.

\section{ACKNOWLEDGEMENTS}

We would like to acknowledge the patients who participated in this study. We would also like to thank the Oncology Unit, Regional Hospital West Jutland and the Section for Radiotherapy in Herning, Department of Oncology, Aarhus University Hospital for generously and positively supporting this study.

\section{CONFlicts of InTEREST Disclosure}

The authors declare that there is no conflict of interest.

\section{REFERENCES}

[1] Fitzmaurice C, et al. Global, Regional, and National Cancer Incidence, Mortality, Years of Life Lost, Years Lived With Disability, and Disability-Adjusted Life-Years for 29 Cancer Groups, 1990 to 2017: A Systematic Analysis for the Global Burden of Disease Study. JAMA Oncol. 2019; 5(12): 1749-1768. PMid:31560378 https://doi.org/10.1001/jamaoncol.2019.2996

[2] National Cancer Institute, "National Cancer Institute," 2021. [Online] Available from: https://www.cancer.gov/about-nci/organ ization/cgh/blog/2017/breast-cancer

[3] Veronesi U, Boyle P, Goldhirsch A, et al. Breast cancer. Lancet. 2005; 365(9472): 1727-1741. https://doi.org/10.1016/S0140-673 $6(05) 66546-4$

[4] American Cancer Society, "Managing Cancer as a Chronic Illness," 2021. [Online]. Available from: https: //www. cancer.org/treatment/survivorship-during-and -after-treatment/when-cancer-doesnt-go-away.html

[5] Kristensen IV, et al. The transitional experience of women with newly diagnosed breast cancer. J. Nurs. Educ. Pract. 2019; 9(6): 23. https://doi.org/10.5430/jnep.v9n6p23

[6] Ganz PA, et al. Quality of life at the end of primary treatment of breast cancer: first results from the moving beyond cancer randomized trial. J. Natl. Cancer Inst. 2004; 96(5): 376-87. PMid:14996859 https://doi.org/10.1093/jnci/djh060

[7] Langer AS. Side effects, quality-of-life issues, and trade-offs: the patient perspective. J. Natl. Cancer Inst. Monogr. 2001; 30: 125-9. PMid:11773305 https://doi.org/10.1093/oxfordjournals .jncimonographs.a003449
[8] Jorgensen 1. Distress among women taking part in surgical continuity of care for breast cancer: a mixed methods study. Aalborg University Press; 2015.

[9] Biering K, Frydenberg M, Pappot H, et al. The long-term course of fatigue following breast cancer diagnosis. J. Patient-Reported Outcomes. 2020; 4(1): 37. PMid:32424569 https ://doi.org/10.1 186/s41687-020-00187-9

[10] Mertz BG, et al. Psychological distress among women with newly diagnosed breast cancer. Eur. J. Oncol. Nurs. 2012; 16(4): 439-443. PMid:22036771 https://doi.org/10.1016/j.ejon.2011.10 .001

[11] Ng CG, et al. Perceived distress and its association with depression and anxiety in breast cancer patients. PLoS One. 2017; 12(3): e0172975. PMid:28296921 https ://doi .org/10.1371/journa 1.pone. 0172975

[12] Johnsson A, Fornander T, Rutqvist LE, et al. Predictors of return to work ten months after primary breast cancer surgery. Acta Oncol 2009; 48(1): 93-8. PMid:18937082 https ://doi.org/10.1080/ 02841860802477899

[13] Boehmke MM, Dickerson SS. The diagnosis of breast cancer: transition from health to illness. Oncol. Nurs. Forum. 2006; 33(6): 11211127. PMid:17149395 https://doi.org/10.1188/06. ONF. 112 1-1127

[14] Burris JL, Armeson K, Sterba KR. A closer look at unmet needs at the end of primary treatment for breast cancer: a longitudinal pilot study. Behav. Med. 2015; 41(22): 69-76. PMid:24512316 https ://doi.org/10.1080/08964289.2014.889068

[15] Harrison JD, Young JM, Price MA, et al. What are the unmet supportive care needs of people with cancer? A systematic review. 
Support. Care Cancer. 2009; 17(8): 1117-1128. PMid:19319577 https://doi.org/10.1007/s00520-009-0615-5

[16] Henriksen J, Kristensen IV, Meldgaard A, et al. Rejsen gennem ingenmandsland. Nord. sygeplejeforskning. 2019; 9(1): 59-71. https : //doi.org/10.18261/issn.1892-2686-2019-01-06

[17] JAVA. Declaration of Helsinki World Medical Association Declaration of Helsinki. Bull. world Heal. Organ. 2013; 79(4): 373-374.

[18] World Medical Association. Declaration of Helsinki, Ethical Principles for Scientific Requirements and Research Protocols. Bull. World Health Organ. 2013; 79(4): 373.

[19] Boyes A, Girgis A, Lecathelinais C. Brief assessment of adult cancer patients' perceived needs: Development and validation of the 34-item supportive care needs survey (SCNS-SF34). J. Eval. Clin. Pract. 2009; 15(4): 602-606. PMid:19522727 https ://doi.org/ $10.1111 / j .1365-2753.2008 .01057 . x$

[20] Brédart A, et al. Validation of the 34-item Supportive Care Needs Survey and 8-item Breast module French versions (SCNS-SF34-Fr and SCNS-BR8-Fr) in breast cancer patients. Eur. J. Cancer Care (Engl). 2012.

[21] Schofield P, Gough K, Lotfi-Jam K, et al. Validation of the supportive care needs survey-short form 34 with a simplified response format in men with prostate cancer. Psychooncology. 2012; 21(10): 1107-1112. PMid:21800397 https://doi.org/10.1002/pon.2016

[22] S. W.K.W, et al. Validation of the Chinese version of supportive care needs survey and supplementary module of access to health care services. Supportive Care in Cancer. 2011.

[23] Hu CC, et al. Validation of the Supportive Care Needs Survey Screening Tool Chinese Version for Patients with Head and Neck Cancer in Taiwan. J. Nurs. Res. 2019.

[24] Au A, et al. Validation of the Chinese version of the Short-form Supportive Care Needs Survey Questionnaire (SCNS-SF34-C). Psychooncology. 2011.

[25] A. Zeneli, et al. Translation of Supportive Care Needs Survey Short Form 34 (SCNS-SF34) into Italian and cultural validation study. Support. Care Cancer. 2016.

[26] Rietveld MJA, et al. Psychometric properties of the 45-item supportive care needs survey - partners and caregivers - Dutch (SCNSP\&C45-D) in partners of patients with breast cancer. J. PatientReported Outcomes. 2019. PMid:30635737 https://doi .org/10 .1186/s41687-019-0092-7

[27] Furlanetto LM, Mendlowicz MV, Romildo Bueno J. The validity of the Beck Depression Inventory-Short Form as a screening and diagnostic instrument for moderate and severe depression in medical inpatients. J. Affect. Disord. 2005; 86(1): 87-91. PMid:15820275 https://doi.org/10.1016/j.jad.2004.12.011

[28] Beck AT. Steer RA, Carbin MG. Psychometric properties of the Beck Depression Inventory: Twenty-five years of evaluation. Clin. Psychol. Rev. 1988; 8(1): 77-100. https://doi.org/10.1016/0272-735 8(88) 90050-5

[29] Beck A, Steer R, Brown G. Beck Depression Inventory-II (BDI-II). Beck Depress. Invent. 1993.

[30] Zachariae R, Zachariae C, Ibsen HHW, et al. Psychological symptoms and quality of life of dermatology outpatients and hospitalized dermatology patients. Acta Derm. Venereol. 2004; 84(3): 205-212. PMid:15202837 https://doi.org/10.1080/00015550410023 284

[31] Love AW, Grabsch B, Clarke DM, et al. Screening for depression in women with metastatic breast cancer: a comparison of the Beck Depression Inventory Short Form and the Hospital Anxiety and Depression Scale. Aust N Z J Psychiatry. 2004; 38(7): 526-531. PMid:15255825 https://doi.org/10.1080/j.1440-1614.20 $04.01385 . x$

Published by Sciedu Press
[32] Horowitz M, Wilner N, Alvarez M. Impact of event scale: A measure of subjective stress. Psychosom. Med. 1979; 41(3): 209-218. PMid:472086 https://doi.org/10.1097/00006842-1979050 00-00004

[33] Groenvold M, Klee MC, Sprangers MAG, et al. Validation of the EORTC QLQ-C30 quality of life questionnaire through combined qualitative and quantitative assessment of patient-observer agreement. J. Clin. Epidemiol. 1997; 50(4): 441-450. https ://doi .org/10.1 016/S0895-4356 (96) 00428-3

[34] Fayers P, Aaronson N, Bjordal K, et al. The EORTC QLQ-C30 Scoring Manual (3rd Edition). European Organisation for Research and Treatment of Cancer. 2001.

[35] Lepore SJ, Silver RC, Wortman CB, et al. Social constraints, intrusive thoughts, and depressive symptoms among bereaved mothers. J. Pers. Soc. Psychol. 1996; 70(2): 271-282. PMid:8636882 https://doi.org/10.1037/0022-3514.70.2.271

[36] Lepore SJ, Helgeson VS. Social constraints, intrusive thoughts, and mental health after prostate cancer. J. Soc. Clin. Psychol. 1998; 17(1): 89-106. https://doi.org/10.1521/jscp.1998.17.1.89

[37] Rasmusson EM, Plantin L, Elmerstig E. 'Did they think I would understand all that on my own?' A questionnaire study about sexuality with Swedish cancer patients. Eur. J. Cancer Care (Engl). 2013; 22(3): 361-369. PMid:23350636 https : //doi .org/10.1111/ec c. 12039

[38] Schafer JL, Graham JW. Missing data: Our view of the state of the art. Psychol. Methods. 2002; 7(2): 147-177. PMid:12090408 https://doi.org/10.1037/1082-989X .7.2.147

[39] Cohen J. Statistical Power analysis for the ... Ect. in Statistical Power Anaylsis for the Behavioural Science. 2nd ed. 1988.

[40] Juul T, Petersen MA, Holzner B, et al. Danish population-based reference data for the EORTC QLQ-C30: associations with gender, age and morbidity. Qual. Life Res. 2014; 23(8): 2183-2193. PMid:24676897 https://doi .org/10.1007/s11136-014-067 $5-\mathrm{y}$

[41] Nolte S, et al. General population normative data for the EORTC QLQ-C30 health-related quality of life questionnaire based on 15,386 persons across 13 European countries, Canada and the Unites States. Eur. J. Cancer. 2019; 107: 153-163. PMid:30576971 https://doi.org/10.1016/j.ejca.2018.11.024

[42] Jensen-Johansen MB, et al. Effects of an expressive writing intervention on cancer-related distress in Danish breast cancer survivors Results from a nationwide randomized clinical trial. Psychooncology. 2013; 22: 7. PMid:22991162 https://doi.org/10.1002/pon. 3193

[43] Danish Cancer Society. Danish Cancer Society," Kræftpatienters behov og oplevelser med sundhedsvæsenet i opfølgnings-og efterforløbet, 2019. [Online]. Available from: file:///X:/Brystkr TT1 \aeftartikel/kraeftens-bekae mpelses-barometerundersoegelse-2019.pdf

[44] Meleis AI, Sawyer LM, Im EO, et al. Experiencing transitions: an emerging middle-range theory. ANS. Adv. Nurs. Sci. 2000; 23(1): 12-28. PMid:10970036 https://doi.org/10.1097/00012272 $-200009000-00006$

[45] Drolet M, Maunsell E, Brisson J, et al. Not working 3 years after breast cancer: predictors in a population-based study. J. Clin. Oncol. 2005; 23(33): 8305-8312. PMid:16219927 https://doi .org/10 $.1200 / \mathrm{JCO} .2005 .09 .500$

[46] Hamood R, Hamood H, Merhasin I, et al. Work Transitions in Breast Cancer Survivors and Effects on Quality of Life. J. Occup. Rehabil. 2019; 29(2): 336-349. PMid:29948472 https://doi.org/10.1 007/s10926-018-9789-3 
[47] Tiedtke C, de Rijk A, Dierckx de Casterlé B, et al. Experiences and concerns about 'returning to work' for women breast cancer survivors: a literature review. Psychooncology. 2010; 19(7): 677-83. PMid:19823971 https://doi.org/10.1002/pon.1633

[48] Tiedtke CM, et al. Employers' experience of employees with cancer: trajectories of complex communication. J. Cancer Surviv. 2017;
11(5): 562-577. PMid:28710544 https://doi.org/10.1007/s1 1764-017-0626-z

[49] Male DA, Fergus KD, Cullen K. Sexual identity after breast cancer: sexuality, body image, and relationship repercussions. Curr. Opin. Support. Palliat. Care. 2016; 10(1): 66-74. PMid:26716393 https://doi.org/10.1097/SPC. 0000000000000184 